\title{
Generation of Transgenic Papaya with Double Resistance to Papaya ringspot virus and Papaya leaf-distortion mosaic virus
}

\author{
Yi-Jung Kung, Huey-Jiunn Bau, Yi-Ling Wu, Chiung-Huei Huang, Tsui-Miao Chen, and Shyi-Dong Yeh
}

First, third, fourth, fifth, and sixth authors: Department of Plant Pathology, National Chung Hsing University, Taichung, Taiwan, R.O.C.; and second author: Department of Biotechnology, Transworld Institute of Technology, Yunlin, Taiwan, R.O.C. Accepted for publication 7 July 2009.

\begin{abstract}
Kung, Y.-J., Bau, H.-J., Wu, Y.-L., Huang, C.-H., Chen, T.-M., and Yeh, S.-D. 2009. Generation of transgenic papaya with double resistance to Papaya ringspot virus and Papaya leaf-distortion mosaic virus. Phytopathology 99:1312-1320.

During the field tests of coat protein (CP)-transgenic papaya lines resistant to Papaya ringspot virus (PRSV), another Potyvirus sp., Papaya leaf-distortion mosaic virus (PLDMV), appeared as an emerging threat to the transgenic papaya. In this investigation, an untranslatable chimeric construct containing the truncated $\mathrm{CP}$ coding region of the PLDMV PTW-WF isolate and the truncated CP coding region with the complete $3^{\prime}$ untranslated region of PRSV YK isolate was transferred into papaya (Carica papaya cv. Thailand) via Agrobacterium-mediated transformation to generate transgenic plants with resistance to PLDMV and PRSV.

YK or PLDMV P-TW-WF by mechanical inoculation under greenhouse conditions. Thirty-eight transgenic lines showing no symptoms 1 month after inoculation were regarded as highly resistant lines. Southern and Northern analyses revealed that four weakly resistant lines have one or two inserts of the construct and accumulate detectable amounts of transgene transcript, whereas nine resistant lines contain two or three inserts without significant accumulation of transgene transcript. The results indicated that double virus resistance in transgenic lines resulted from double or more copies of the insert through the mechanism of RNA-mediated posttranscriptional gene silencing. Furthermore, three of nine resistant lines showed high levels of resistance to heterologous PRSV strains originating from Hawaii, Thailand, and Mexico. Our transgenic lines have great potential for controlling a number of PRSV strains and PLDMV in Taiwan and elsewhere.
\end{abstract} Seventy-five transgenic lines were obtained and challenged with PRSV
Papaya (Carica papaya L.) is an economically important fruit crop widely grown in tropical and subtropical areas. The destructive disease caused by Papaya ringspot virus (PRSV) is a major obstacle for large-scale production of papaya (33). PRSV, first found in the southern area of Taiwan in 1975 (45), has destroyed most of the papaya plantations on the island $(46,50,52)$. The virus belongs to the genus Potyvirus of the family Potyviridae (15). It has a positive-sense RNA genome (35) and is transmitted by aphids in a nonpersistent manner (33). The viral RNA is translated into a polyprotein that is processed by three viral proteases to generate all final viral proteins $(49,53)$.

Natural sources of resistance against PRSV in $C$. papaya is not available for conventional breeding $(11,12)$. Effective strategies to control PRSV include the application of cross protection with mild PRSV strain HA5-1 (48) or pathogen-derived resistance (PDR) with transgenic papaya carrying the coat protein $(\mathrm{CP})$ gene (16). Cross protection as a control measure was widely used as a routine practice in Taiwan for a decade until 1994 (46,48,50,52), when superinfection by heterologous PRSV strains was noticed (50). Transgenic papaya carrying the CP gene of PRSV HA 5-1 (48) via microprojectile bombardment (16) is highly resistant to the severe Hawaiian HA strain under glasshouse and field conditions $(17,28)$. The resistance is affected by the sequence divergence between the $\mathrm{CP}$ transgene and the $\mathrm{CP}$ coding region of the challenge virus $(10,39)$ and is dosage dependent (38). The CPhemizygous line Rainbow is susceptible to non-Hawaiian PRSV

Corresponding author: S.-D. Yeh; E-mail address: sdyeh@nchu.edu.tw

*The $\boldsymbol{e}$-Xtra logo stands for "electronic extra" and indicates that Figure 2 appears in color online.

doi:10.1094/PHYTO-99-11-1312

(c) 2009 The American Phytopathological Society isolates. Although the CP-homozygous line SunUp is resistant to a wider range of isolates from Jamaica and Brazil, it is still susceptible to isolates from Thailand and Taiwan $(20,21,38)$. Papaya cultivars Rainbow and SunUp have been commercialized in Hawaii since 1998, representing the first practical application of transgenic fruit crop $(21,42)$. The characteristic of sequencehomology-dependent resistance, however, limits the application of CP-transgenic papaya for controlling PRSV in geographic regions other than Hawaii.

Transgenic papaya lines carrying the CP gene of a Taiwanese strain, PRSV YK, were successfully generated from our laboratory (9). They provide resistance to the homologous strain and geographically distinct strains of PRSV (2). Results from a 4-year (1996-99) field evaluation indicate that the YK CP transgenic lines provide new germplasm for managing PRSV in Taiwan (3). During the test period, a few transgenic papaya plants expressing the YK CP gene exhibited severe symptoms similar to those of PRSV infection. A virus, designated as P-TW-WF, was isolated from an infected YK CP transgenic plant and was identified as a strain of another Potyvirus sp., Papaya leaf-distortion mosaic virus (PLDMV) $(4,8)$, which is serologically distinct from PRSV. PLDMV was first recorded in the northern part of Okinawa Island, Japan, in 1954 (54), and spread throughout the island during 1960s (25). The disease caused by PLDMV has been a major constraint to papaya production in Okinawa, Japan (30). The CP genes of the P-TW-WF isolate from Taiwan and the P56 isolate of Okinawa (30) share $95.1 \%$ nucleotide and $94.9 \%$ amino acid identities (4).

Field surveys with the antiserum against the bacteria-expressed $\mathrm{CP}$ of P-TW-WF revealed a scattered occurrence of PLDMV in Taiwan (4). Unlike the cucurbit-infecting Japanese P type isolates $(29,30)$, the Taiwanese isolates infect only papaya and are considered to be a new pathotype of PLDMV (4). The susceptibility 
of all PRSV-resistant transgenic papaya lines to PLDMV indicates that the virus is an emerging threat for the application of PRSV-resistant transgenic papaya in Taiwan and elsewhere (4).

Transgenic plants with multiple-virus resistance can be generated by transferring a T-DNA fragment containing individual $\mathrm{CP}$ gene sequences of different viruses, each driven by a promoter and a terminator (18). Transgenic lines expressing multiple $\mathrm{CP}$ genes were resistant to the corresponding viruses and were protected from mixed infection $(18,19,40)$. Alternatively, transgenic plants with resistance to a potyvirus and a tospovirus were obtained by fusing a segment of the tospoviral $\mathrm{N}$ gene to the potyviral CP gene (23). Also, simultaneous targeting of four different Tospovirus spp. has also been achieved using a single small transgene based on the production of minimal-sized chimeric cassettes (7).

In this study, we use the chimeric construct strategy to develop double-virus resistance to both PRSV and PLDMV. An untranslatable chimeric construct containing a fused cDNA fragment composed of the truncated PLDMV P-TW-WF CP and PRSV YK $\mathrm{CP}$ coding regions was transferred to papaya via Agrobacterium spp.-mediated transformation. The transgenic papaya lines carrying the chimeric construct were regenerated and micropropagated. The results of greenhouse evaluation indicate that our transgenic papaya lines have great potential for control of both PRSV and PLDMV.

\section{MATERIALS AND METHODS}

Construction of an untranslatable chimeric construct. The construct pPLDMVCP, containing a cDNA fragment with the complete $\mathrm{CP}$ coding region and the entire $3^{\prime}$ noncoding region of P-TW-WF, was previously generated in our laboratory (4). For polymerase chain reaction (PCR), the primer PLDMVstop (5'CCATGGAGTCCGCTCTTTGATGATGG-3') containing an NcoI site (underlined), a $\mathrm{T}$ insert (underlined) to create a opal stop codon and frame-shift (shown bold), and a $\mathrm{C}$ substituted by $\mathrm{A}$ (underlined) to generate a second opal stop codon (shown bold), was used as the forward primer, and the primer $\mathrm{dT}_{18} \mathrm{SacI}\left(5^{\prime}-\right.$ TTTTTTTTTTTTTTTTTTGAGCTCT, SacI site underlined) was used as the reverse primer. A 1.1-kb PCR DNA fragment containing the frame-shifted $\mathrm{CP}$ reading frame and the $3^{\prime}$ noncoding region of P-TW-WF RNA was amplified using pPLDMVCP as a template with the described primers. This fragment was cloned into the TOPO PCR-II vector (Invitrogen, Carlsbad, CA) to generate pPLDMVstop (Fig. 1). The NcoI/SmaI fragment of the pPLDMVstop was linked, through blunt-end ligation, to $\mathrm{NcoI} /$ SwaI-digested pBGCP that contained a cDNA fragment containing the entire $\mathrm{CP}$ reading frame and the whole $3^{\prime}$ noncoding sequence of PRSV (9) to generate the construct pPY16 (Fig. 1). The final construct was transformed into Agrobacterium tumefaciens LBA4404 by the triparental mating method (34).

Generation of transgenic papaya lines. Papaya transformation and regeneration were carried out following the method developed by Cheng et. al. (9) with modifications. The embryogenic tissues, derived from immature zygotic embryos of papaya (C. papaya $\mathrm{cv}$. Thailand), were wounded in liquid-phase with 600-mesh carborundum by vortexing and co-cultured with Agrobacterium spp. carrying pPY16 for 2 days. After washing with sterile water, the treated explants were cultured on plates with the medium containing carbenicillin at $500 \mathrm{mg} / \mathrm{liter}$ to suppress the bacteria and then transferred three times on the selection medium containing carbenicillin at $500 \mathrm{mg} / \mathrm{liter}$ and kanamycin at $100 \mathrm{mg} / \mathrm{liter}$ (9), each for 1 month of culturing. The putative transformed calli were transferred to the same medium without kanamycin to enhance the formation of somatic embryos (55). After 2 to 4 weeks, the somatic embryos derived from the selected transformed cells were germinated on a germination medium (47). Individual shoots regenerated and were then multiplied in a

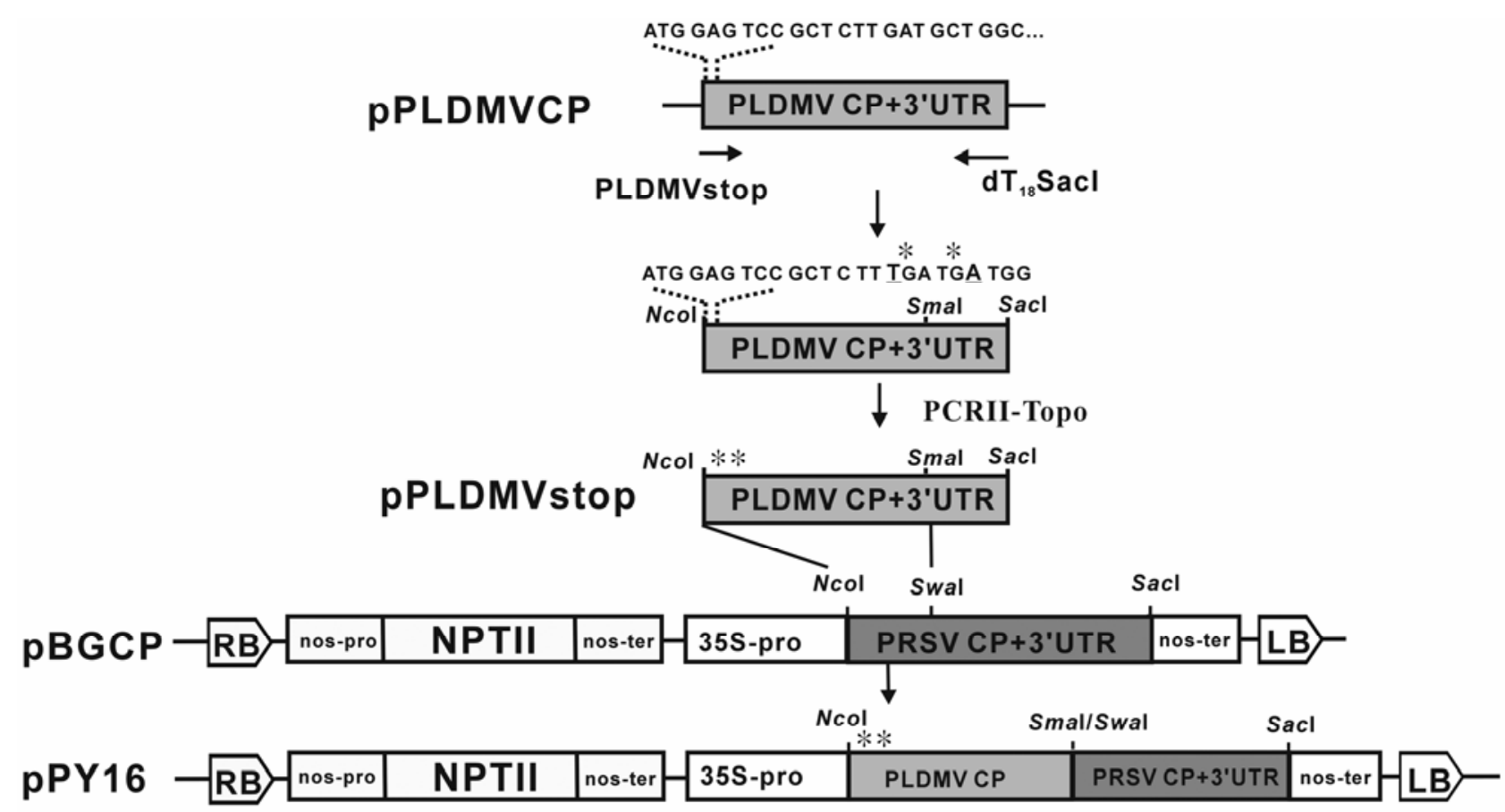

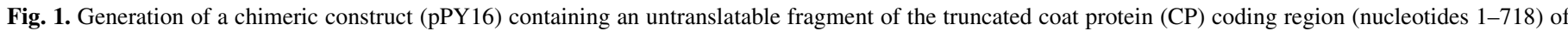

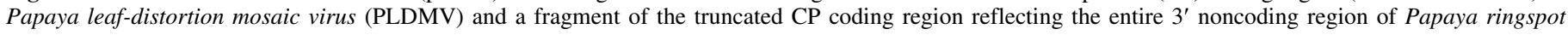

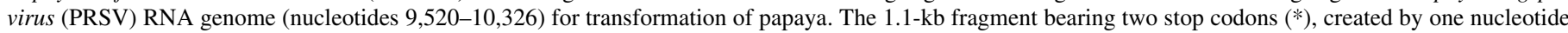

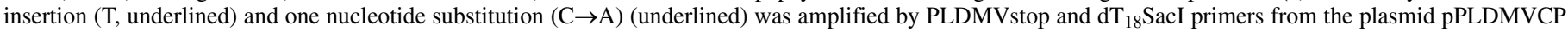

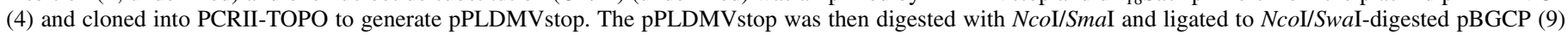

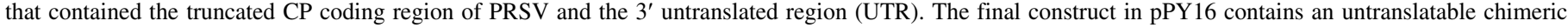

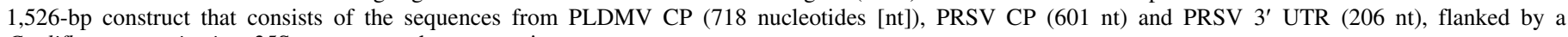
Cauliflower mosaic virus $35 \mathrm{~S}$ promoter and a nos terminator. 
micropropagation medium (47) to form multiple shoots which were excised and rooted as described (9). The putative transformed plantlets micropropagated from a single original shoot were acclimatized in a growth chamber and then established in vermiculite soil under temperature-controlled $\left(25 \pm 3^{\circ} \mathrm{C}\right)$ greenhouse conditions (9). The micropropagated plants of individual $\mathrm{R}_{0}$ lines were used for further evaluation.

DNA extraction and PCR. Total DNA was extracted from leaves of putative transgenic papaya lines or untransformed papaya plants using DNeasy Plants Mini kit (Qiagen, Valencia, CA). The plasmid DNA of pPY16 was used as a positive control for PCR. RNase A-treated DNA ( $1 \mu \mathrm{g})$ was used for PCR with the forward primer PLDMVstop (5'-CCATGGAGTCCGCTCTTTGATGATGG-3') and the reverse primer MO1008 (5'-GTGCATGTCTCTGTTGACAT-3'), containing nucleotides positions 1 to 26 and 1,272 to 1,291 of the chimeric CP construct, respectively. PCR was performed using a temperature profile of $1 \mathrm{~min}$ at $94^{\circ} \mathrm{C}$, $2 \mathrm{~min}$ at $55^{\circ} \mathrm{C}$, and $3 \mathrm{~min}$ at $72^{\circ} \mathrm{C}$ for 30 cycles. Additionally, $n p t$ II-specific primers NA (5'-CCCCTCGGTATCCAATTAGA-3') and NB (5'-GTGGGCGAAGAA CTCCAG-3') were used in PCR to analyze for the presence of the selection marker.

Inoculation of putative transgenic lines with PRSV YK or PLDMV P-TW-WF. The virus resistance of putative transgenic lines was evaluated by mechanical inoculation with PRSV YK (44) or PLDMV P-TW-WF (4) in a temperature-controlled (25 \pm $3^{\circ} \mathrm{C}$ ) greenhouse. Seventy-five transgenic lines (six plants/line) were inoculated with PRSV or PLDMV. Micropropagated $\mathrm{R}_{0}$ transgenic papaya plantlets were grown to a height of 5 to $6 \mathrm{~cm}$ in a temperature-controlled greenhouse. The first two fully expanded leaves were dusted with 600-mesh carborundum and rubbed with $200 \mu$ of inoculum that was prepared from papaya leaf tissue 3 weeks after inoculation with PRSV YK or PLDMV P-TW-WF (1:10 [wt/vol] in 0.01 $\mathrm{M}$ potassium phosphate buffer, $\mathrm{pH} 7.0)$. Nontransgenic papaya plants (cv. Thailand) were used as controls. Plants were kept in a temperature-controlled greenhouse (25 \pm $3^{\circ} \mathrm{C}$ ) and symptom development was monitored for 7 weeks.

Inoculation with different geographic PRSV strains. In all, 13 transgenic lines - 4 weakly resistant (WR) lines (2-3, 6-3, 7-5, and 21-2) and 9 highly resistant (HR) lines (5-3, 5-4, 9-5, 10-4, $12-4,14-1,14-3,17-4$, and 29-2)-were grown to 15 to $18 \mathrm{~cm}$ high for further evaluation. At least 10 plants from each lines were further tested against geographically distinct strains of PRSV originating from Hawaii (HA) (22), Thailand (TH), and Mexico (MX) (2). All virus strains were propagated in papaya cv. Tainung No. 2 and inocula were prepared 21 days after inoculation $(1: 10$ [wt/vol] in $0.01 \mathrm{M}$ potassium phosphate buffer, $\mathrm{pH}$ 7.0). Disease incidence and symptom development were monitored for 7 weeks after inoculation.

Indirect enzyme-linked immunosorbent assays. Indirect enzyme-linked immunosorbent assay (ELISA) was performed as described previously (51). Leaf extracts diluted in $50 \mathrm{mM}$ sodium carbonate buffer ( $\mathrm{pH} 9.6$ ) with $0.01 \%$ sodium azide were used to coat the wells of a polystyrene microtiter plate. The P-TW-WF CP antiserum (4) or PRSV CP antiserum (51), diluted 2,000-fold in conjugate buffer (51), was added $(200 \mu \mathrm{l} /$ well) and incubated at $37^{\circ} \mathrm{C}$ for $1 \mathrm{~h}$. After washing the wells three times, $200 \mu \mathrm{l}$ of alkaline phosphatase-conjugated goat anti-rabbit immunoglobulin (KPL, Inc., Gaithersburg, MD), diluted 5,000-fold in conjugate buffer, was added to each well. After washing, $100 \mu$ of $p$-nitrophenyl phosphate at $1 \mathrm{mg} / \mathrm{ml}$ (Sigma-Aldrich Corporation, St. Louis) in substrate buffer (100 mM diethanolamine, $\mathrm{pH}$ 9.6) was added to each well. The absorbance at $405 \mathrm{~nm}$ was measured with a Rainbow microplate reader (SLT Lab Instruments, Salzburg, Austria) 30 min after the addition of enzyme substrate. The transgenic plants that recorded twofold or more absorbance compared with that of the negative control were classified as ELISA positive.

Southern hybridization. The DNeasy Plant Mini kit (Qiagen) was used to extract genomic DNA of papaya plants. Genomic
DNA $(30 \mu \mathrm{g}$ ) was digested with HindIII (a unique HindIII site is located in the T-DNA between the nptII gene and 35S promoter) and electrophoresed in an agarose gel. The gel was treated with $0.25 \mathrm{~N} \mathrm{HCl}$ for 15 min to depurinate, soaked with denaturation buffer $(1.5 \mathrm{M} \mathrm{NaCl}$ and $0.5 \mathrm{~N} \mathrm{NaOH})$ for $45 \mathrm{~min}$, treated with neutralization buffer ( $1 \mathrm{M}$ Tris and $1.5 \mathrm{M} \mathrm{NaCl}, \mathrm{pH} 7.4$ ) for $30 \mathrm{~min}$, and transferred to Gene Screen Plus nylon membrane (Dupont Co., Boston). The Primer-It II random primer labeling kit (Stratagene, La Jolla, CA) was used to prepare the $\left[\alpha-\mathrm{P}^{32}\right] \mathrm{dATP}-$ labeled probe from a 25-ng DNA fragment $(1.3 \mathrm{~kb})$ amplified from pPY16 using PLDMVstop and MO1008 primers according to manufacturer's instruction. The blotted Gene Screen Plus nylon membrane (Dupont Co.) was treated with prehybridization buffer (1\% [wt/vol] sodium dodecyl sulfate [SDS], $1 \mathrm{M} \mathrm{NaCl}, 10 \%$ [wt/vol] dextran sulfate, and salmon sperm DNA at $100 \mu \mathrm{g} / \mathrm{ml}$ ) at $60^{\circ} \mathrm{C}$ for $1 \mathrm{~h}$ followed by hybridization of the probe at $60^{\circ} \mathrm{C}$ for $16 \mathrm{~h}$. Following hybridization, the membrane was washed with $100 \mathrm{ml}$ of $2 \times \mathrm{SSC}(1 \times \mathrm{SSC}$ is $0.15 \mathrm{M} \mathrm{NaCl}$ plus $0.015 \mathrm{M}$ sodium citrate) with $0.1 \%$ SDS for $15 \mathrm{~min}$ twice, and then washed with $100 \mathrm{ml}$ of $0.1 \times \mathrm{SSC}$ with $0.1 \%$ SDS for $15 \mathrm{~min}$ twice. Autoradiography was carried out at $-80^{\circ} \mathrm{C}$ for $48 \mathrm{~h}$ on $\mathrm{X}$-ray film (Hyperfilm MP, Amersham Phamacia Biotech, UK) with intensifying screens.

Northern hybridization. Total RNA was extracted from young leaves of transgenic and nontransgenic papaya plants by the ULTRASPEC RNA isolation system (Biotecx Laboratories, Houston). Total RNA (15 $\mu \mathrm{g})$ was separated on a $1.2 \%$ agarose gel with formaldehyde, transferred to a Gene Screen Plus nylon membrane (Dupont Co.), and hybridized with the radioactive probe specific to the $\mathrm{CP}$ coding regions of PRSV YK and PLDMV P-TW-WF, prepared as described above, at $60^{\circ} \mathrm{C}$ for 16 h. Prehybridization, hybridization, washing, and autoradiography were carried out as described for Southern hybridization analysis.

Small interfering RNA detection. Total RNA was extracted from young leaves using the Trizol reagent (Invitrogen). Total RNA $(30 \mu \mathrm{g})$ was resolved on a $15 \%$ polyacrylamide/ $1 \times$ Trisborate EDTA (8.9 mM Tris, $8.9 \mathrm{mM}$ boric acid, $20 \mathrm{mM}$ EDTA)/ $8 \mathrm{M}$ urea gel and the separated profile was blotted to a Hybond$\mathrm{N}+$ membrane (Amersham Phamacia Biotech, UK). The Primer-It II random primer labeling kit (Stratagene, La Jolla, CA) was used to prepare the $\left[\alpha-\mathrm{P}^{32}\right] \mathrm{dATP}-$ labeled probe. This radioactive probe derived from PY16 fragment $(1.3 \mathrm{~kb})$ described above in the Southern hybridization was used for detection of small interfering RNA (siRNA). Hybridization was carried out in ULTRAHybOligo solution according to manufacturer's instructions (Ambion Inc., Austin, TX), and siRNA signals were detected by autoradiography as described above. RNA Decade Marker system (Ambion Inc.) was used in this experiment. The Decade Markers were derived from cleavage of a single 150-nucleotide (nt) gelpurified transcript, Decade Marker RNA, which was first 5' endlabeled by kinase reaction with $\left[\gamma-\mathrm{P}^{32}\right]$ ATP according to the manufacturer's instructions to generate a marker set $\approx 10$ to $150 \mathrm{nt}$ in length.

Segregation analysis of transgenic resistance. The papaya $\mathrm{cv}$. Tainung No. 2, a hybrid generated by crossing cv. Sunrise and cv. Thailand, is the most popular commercial cultivar in Taiwan. HR lines 10-4 and 12-4 (C. papaya cv. Thailand) were found to be females. They were crossed with nontransformed hermaphroditic plants of cv. Thailand and cv. Sunrise papaya to generate backcrossed progeny $\left(\mathrm{BC}_{1}\right)$ and hybrid progeny $\left(\mathrm{F}_{1}\right)$, respectively. Seedlings of progenies were first mechanically inoculated with PLDMV P-TW-WF to examine the inheritance of the transgenic resistance. The symptomless seedlings were then mechanically inoculated with PRSV YK. The preparation of the inocula and the method of inoculation were similar to those described for the analysis of $\mathrm{R}_{0}$ plants. All inoculated plants were kept in a temperature-controlled $\left(25 \pm 3^{\circ} \mathrm{C}\right)$ greenhouse for observation. 


\section{RESULTS}

Construction of an untranslatable chimeric construct. Construction of an untranslatable chimeric construct containing a DNA fragment with the truncated PLDMV and PRSV CP coding regions is summarized in Figure 1. The chimeric construct in pPY16 contained a cDNA fragment corresponding to 1-718 of the PLDMV CP reading frame with an inserted $\mathrm{T}$ and a substituted $\mathrm{A}$ to create frame-shift with two opal stop codons at the 5'-terminal region, and a cDNA fragment reflecting the $\mathrm{C}$-terminal $\mathrm{CP}$ coding region (601 nt) and the complete $3^{\prime}$ untranslated region (UTR) (206 nt) of PRSV YK RNA. The total untranslatable chimeric sequence contained $1,526 \mathrm{nt}$, flanked by a Cauliflower mosaic virus $35 \mathrm{~S}$ promoter and a nos terminator (Fig.1).

Establishment of transgenic lines. The embryogenic tissues derived from immature zygotic embryos of papaya (C. papaya $\mathrm{cv}$. Thailand) were transformed with an Agrobacterium sp. carrying pPY16. Somatic embryos that developed from putative transformed cells of calli after selection on the kanamycin medium for 4 months were further cultured on the medium without kanamycin for 1 month. Two to four weeks after culturing on germination medium, shoots developed from somatic embryos. Multiple shoots were obtained 4 weeks after a single shoot was micropropagated on shoot forming medium containing kanamycin at $100 \mathrm{mg} /$ liter. Individual shoots of 1.0 to $1.5 \mathrm{~cm}$ were transferred to the rooting media. When the original putative transgenic papaya shoots were analyzed by PCR using chimeric constructspecific primers, an expected 1.3-kb DNA fragment was amplified from transgenic lines but not from nontransgenic plants (Fig. 2A, upper panel). All selective transgenic lines were also positive when analyzed for the presence of the $n p t$ II gene by PCR (Fig. 2A, lower panel). At least six micropropagated plantlets derived from each of the 75 individual $\mathrm{R}_{0}$ lines were established and used for further assays. In naming, the first numeral of each transgenic line represents the plate number of the first transfer after cocultivation and the second numeral, following after a hyphen, is the actual transgenic line number obtained from that particular plate. Thus, a transgenic line with different first numerals should result from different transformation events.

Inoculation of transgenic lines with PRSV YK or PLDMV P-TW-WF. Micropropagated plants of $75 \mathrm{R}_{0}$ lines (six for each line) with a height of 5 to $6 \mathrm{~cm}$ were mechanically challenged with PRSV YK or PLDMV under greenhouse conditions. Two weeks after inoculation, both nontransgenic papaya plants and 20 transgenic lines showed vein-clearing and mosaic symptoms (six plants/line), typical of PRSV on newly emerged leaves (Table 1; Fig. 2B, a). The $20 \mathrm{PRSV}$ susceptible lines (six plants/line) were also susceptible to PLDMV P-TW-WF, showing severe symptoms of leaf-narrowing, distortion, and stunting, similar to symptoms on inoculated nontransgenic control plants, and were classified as susceptible (S) lines (Fig. 2B, b). Infection of symptomatic plants was confirmed by positive ELISA reactions using the antiserum to PRSV (51) or PLDMV (4). Seventeen lines showed 1 to 2 weeks of delay in symptom development (one to six plants/line) when challenged with PRSV YK or PLDMV P-TW-WF and were classified as WR lines (Table 1). The other 38 transgenic lines did not show symptoms (six plants/line) after being challenged with PRSV YK or PLDMV P-TW-WF (Table 1; Fig. 2B, c and d) were classified as HR lines (Table 1). During the 7-week observation period, these 38 transgenic HR lines remained symptomless and were ELISA negative when analyzed with PRSV (51) or PLDMV antiserum (4).

Resistance against different geographic PRSV strains. Four WR lines and nine HR lines were chosen for further study. The results of inoculation of the WR and HR lines with the three heterologous PRSV strains (MX, TH, and HA) are shown in Table 2. Four weeks after inoculation with PLDMV P-TW-WF or PRSV YK, approximately half of inoculated plants of each WR line showed severe symptoms but only two plants in two HR lines showed mild symptoms after inoculation with PLDMV P-TWWF. Furthermore, the WR lines were more susceptible to heterologous PRSV strains TH, HA, and MX than the HR lines. Three HR lines (10-4, 14-1, and 14-3) showed complete resistance to PLDMV P-TW-WF and PRSV YK, MX, TH, and HA. During the 7-week observation period, these three HR lines remained symptomless and were ELISA negative when tested against PRSV or PLDMV antiserum, whereas all symptomatic plants were ELISA positive.

Southern and Northern analyses of $\mathbf{R}_{\mathbf{0}}$ transgenic lines. The copy numbers of the chimeric construct in the four WR and nine HR lines were determined by Southern blotting. The WR lines contained one or two copies of the chimeric construct while the HR lines contained two or three copies (Fig. 3A). The selected 13 lines were further used to analyze the expression levels of the chimeric construct by northern hybridization. The results revealed that all the four WR lines accumulated detectable levels of the chimeric transcript. In contrast, the chimeric transcript was not detected in the nine HR lines (Fig. 3B).

When siRNA of two WR lines (2-3 and 6-3) and two HR lines (10-4 and 12-4) was analyzed by PY16-specific probe, the results revealed that siRNA related to the chimeric construct was detected from the two HR lines but not from the two WR lines (Fig. 3C).

Segregation analysis of transgenic resistance. Segregation analysis of double-virus transgenic resistance of $\mathrm{BC}_{1}$ and $\mathrm{F}_{1}$ progenies generated from two HR lines (10-4 and 12-4) are summarized in Table 3. All nontransgenic control plants exhibited severe symptoms within 14 days postinoculation with PLDMV PTW-WF. Therefore, seedlings showing symptoms within 14 days postinoculation were considered to contain no transgene. Inoculated plants which remained symptomless 14 days after inoculation were considered to contain the chimeric construct. The segregation ratio of $\mathrm{BC}_{1}$ and $\mathrm{F}_{1}$ progenies revealed that the chimeric construct was inserted at two loci in line 10-4 and a single locus in line 12-4. All the symptomless seedlings remained symptomless after inoculation with PRSV YK. Our results indicate that the transgenic resistance to PLDMV P-TW-WF and PRSV YK was nuclearly inherited as a dominant trait.

\section{DISCUSSION}

Transgenic plants with resistance to several viruses can be obtained through RNA-mediated posttranscriptional gene silencing (PTGS) (5). In this study, an untranslatable chimeric construct carrying the truncated $\mathrm{CP}$ coding sequence of PLDMV and the truncated PRSV CP coding sequence with the complete $3^{\prime}$ UTR of PRSV was successfully used for papaya transformation. Thirtyeight lines highly resistant to both PLDMV P-TW-WF and PRSV YK were obtained. In the present study, parts of PLDMV and PRSV CP genes were joined into a single chimeric construct, which can produce a transcript that might be processed into primary siRNAs directed against PLDMV and PRSV RNAs. Apart from this phenomenon, the spreading of secondary siRNAs derived from the PRSV CP part of the transcript to the PLDMV CP part of the transcript can easily happen through the junction (6). These possible molecular events might be attributed to the observed results that higher degrees of the resistance to both viruses are generally linked together in different transgenic lines. Moreover, these selected lines showed resistance to four heterologous PRSV strains from different geographic regions of Hawaii, Thailand, and Mexico. Hence, our results indicate that the doublevirus resistance transgenic papaya lines have great potential for control of PRSV and PLDMV in Taiwan and elsewhere.

Molecular analyses by Southern hybridization revealed that four WR lines contain one or two copies of the construct, whereas the resistant lines contain two or three copies. Because many of 
the lines were originated from different primary plates after cocultivation, as indicated by the first numerals of their names, they should represent different transformation events. For example, although the lines 5-3 to 12-4 showed similar hybridization profiles (Fig. 3A), they are not considered to be clones of a common transformation event. This is further supported by the fact that the host genomic contexts flanking the transgenes in two of these lines (i.e., 10-4 and 12-4) are different after further molecular analyses (data not shown). Their dissimilar flanking sequences indicated that the lines 10-4 and 12-4 were independent lines originated from different transformation events.

The result of Northern hybridization analysis also showed that the WR lines accumulate detectable amounts of the chimeric transcript, whereas no chimeric transcript was detected in the HR lines. Accumulation of siRNA was detected in HR lines while the same was not detected in WR lines. These results indicate that the double-virus resistance of transgenic lines is mediated by the mechanism of RNA-mediated PTGS (5). Also, our results agree with previous studies that virus resistance in transgenic papaya is mediated by PTGS $(2,13,27)$ and that higher levels of RNAmediated resistance against viruses is often associated with the presence of two or more copies of the transgene $(36,37)$.

A 3:1 ratio of segregation analysis of transgenic resistance was shown in the backcross progeny of line 10-4. This segregation result fits with the presence of two copies of the chimeric construct (Table 3; Fig. 3A). We conclude that the two copies of the
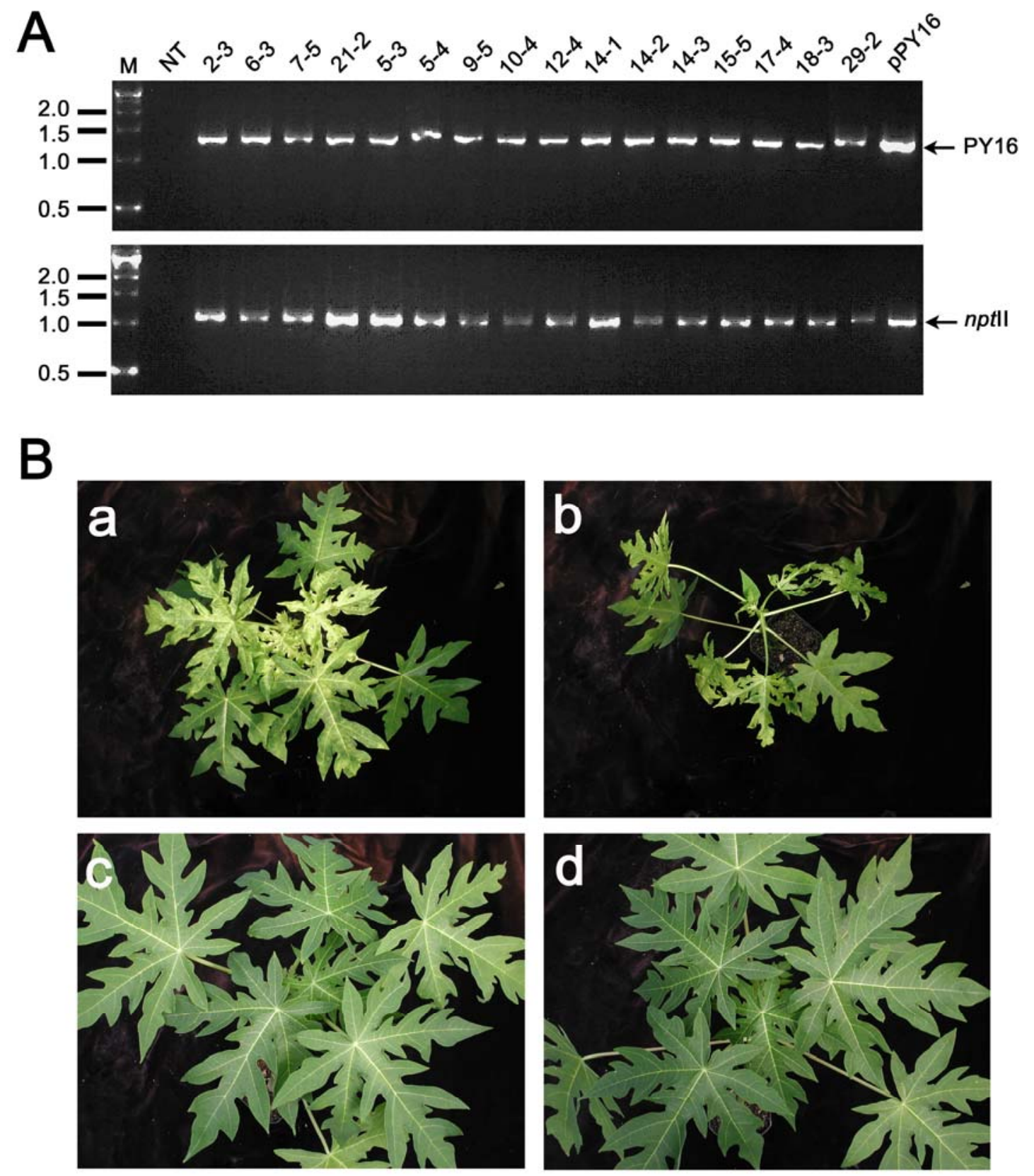

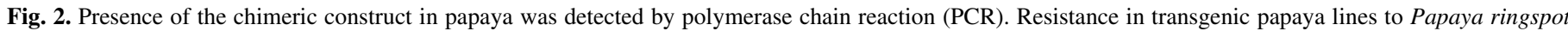

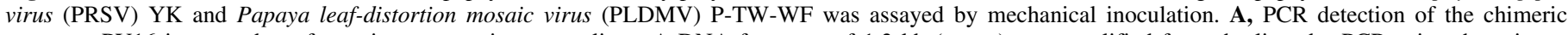

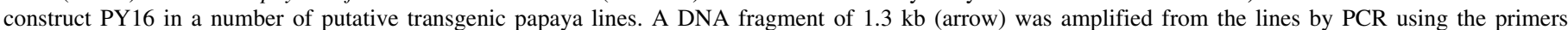

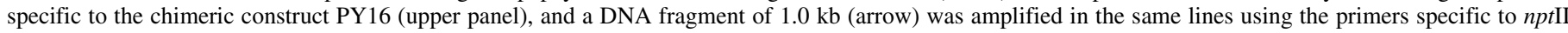

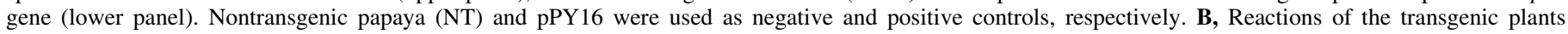

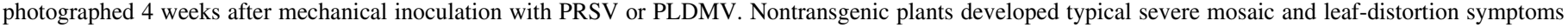

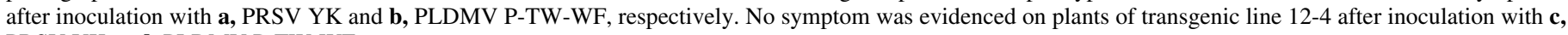
PRSV YK or d, PLDMV P-TW-WF. 
chimeric construct were inserted at different loci in the papaya chromosome and each inherited as a dominant trait following Mendel's heredity. In our previous study, the segregation of the $n p t$ II gene matched well with the segregation of transgenic resistance (2). Therefore, the segregation of $n p t I I$ was not analyzed in this study.

However, a 1:1 ratio for the segregation of the transgenic resistance was found in HR line 12-4 (Table 3), indicating that the two copies of the construct in line 12-4 are closely linked at or near the same locus and fail to segregate in progenies. When the flanking sequences of the T-DNA insert of line 12-4 were elucidated, the results confirmed that the two T-DNA copies of the construct were actually inserted at the same position, as tandem repeat, with the left border of a T-DNA sequence overlapping the right border of the other (data not shown). This explains the presence of two T-DNA copies in line 12-4 (Fig. 3A), but they segregated together as a single copy (Table 3). Furthermore, the host genomic regions flanking the left side of the two transgene copies in line 10-4 were also sequenced. These sequences were different from the sequences of the corresponding region of the transgene in line 12-4 (data not shown).

The WR lines 2-3 and 6-3 produced shorter chimeric transcripts than those produced by 7-5 and 21-2 as revealed by the results of Northern analysis (Fig. 3B). This observation suggests that the integrated T-DNA in lines 2-3 and 6-3 may be partial, probably because of possible loss of the $3^{\prime}$ terminal region during T-DNA delivery to the plant genome. Alternatively, the T-DNA of line 7-5 and 21-2 may be integrated in a locus of host genome with a stronger transcription terminator to generate a longer transgenic transcript. This surmise of the flanking sequences and the T-DNA border sequences of the inserted T-DNA in the papaya genome of these lines remains to be further investigated.

A threshold of RNA accumulation is considered crucial for transgene-induced silencing of homologous viral RNAs (5). PTGS is sensitive to relatively small changes in the amount of transgene transcripts produced (14). Moreover, PTGS can be affected by a number of factors; for example, gene dosage (38), environmental conditions $(26,32,43)$, developmental stage $(2,38)$, and transgene construction (38). PRSV CP-transgenic papaya lines exhibit higher levels of broad-spectrum resistance as their growing stages increased (2). Of the four WR lines tested, all showed severe symptoms 28 days postinoculation when inoculated with PRSV or PLDMV at a height of $\approx 5$ to $6 \mathrm{~cm}$ (Table 1) but $\approx 10$ to $70 \%$ of the plants did not show symptoms 28 days postinoculation if inoculated when the plants attained a height of $\approx 15$ to $18 \mathrm{~cm}$ (Table 2 ). The results indicated that the resistance levels increase when the seedlings mature.

The resistance induced by PTGS provides a high degree of protection but is highly strain specific due to its sequence-homology-dependent nature (31). When challenged with different geographic PRSV strains, three HR lines (10-4, 14-1, and 14-3) showed complete resistance to PRSV YK, HA, MX, and TH, indicating that they have great potential for the control of PLDMV and different PRSV strains. Unfortunately, these three lines were found to be susceptible to PRSV isolate 5-19 (data not shown), which is able to overcome the PSRV YK CP gene-mediated resistance of papaya lines (41). Thus, certain PRSV strains like 5-19 will probably remain a threat to our transgenic papaya with double-virus resistance. Because isolate 5-19 (41) was found after the PLDMV isolate that was recorded in 1999 (8), we did not use its $\mathrm{CP}$ gene for construction of the chimeric construct in this study.

Comparison of nucleotide identities of coding regions and $3^{\prime}$ UTRs of other geographic PRSV strains with those of PRSV YK indicates that the sequences of the $\mathrm{CP}$ coding region and the $3^{\prime}$ UTRs of isolate 5-19 are less divergent to the YK strain than to PRSV HA, MX, and TH (41). In spite of being more closely related to the YK strain, the 5-19 isolate is capable of overcoming resistance PRSV CP-expressing transgenic lines (41). This result indicates that the ability of PRSV isolate 5-19 to break transgenic resistance is not due to sequence divergence of PRSV 5-19 CP from the PRSV YK CP transgene. Instead, the PRSV 5-19 genome may contain a certain genetic determinant which involves overcoming the transgenic resistance in papaya provided by the

TABLE 1. Evaluation of resistance of transgenic papaya lines by mechanical inoculation with Papaya ringspot virus (PRSV) YK or Papaya leaf-distortion mosaic virus (PLDMV) P-TW-WF under greenhouse conditions

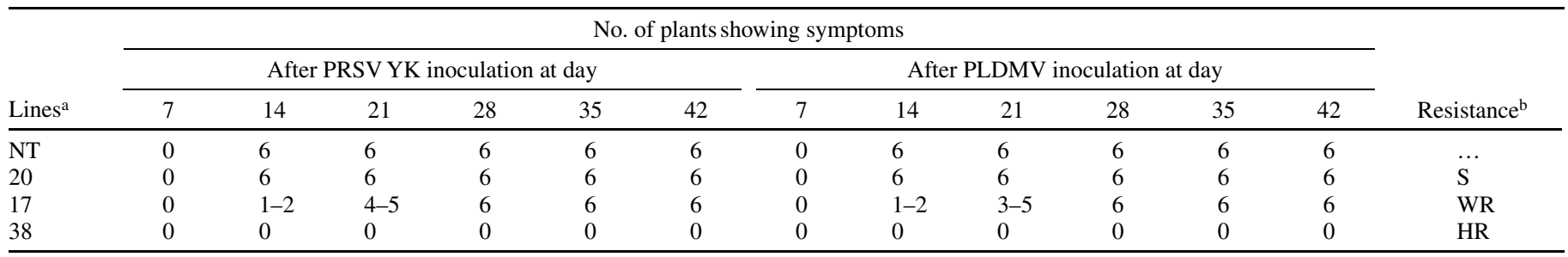

a Total numbers of putative transgenic lines. NT = nontransgenic papaya. At least six plants from each line were tested by mechanical inoculation with PRSV or PLDMV P-TW-WF.

${ }^{\mathrm{b}}$ Resistance level. Transgenic lines that showed no delay in development of severe symptoms when compared with NT were rated as susceptible (S), those showing a delay in symptom expression for 1 to 2 weeks were rated as weakly resistant (WR), and those showing no symptoms 6 weeks after inoculation were considered as highly resistant (HR).

TABLE 2. Responses of transgenic papaya lines to Papaya leaf-distortion mosaic virus (PLDMV) P-TW-WF and four strains of Papaya ringspot virus (PRSV) originated from different geographic areas ${ }^{\mathrm{a}}$

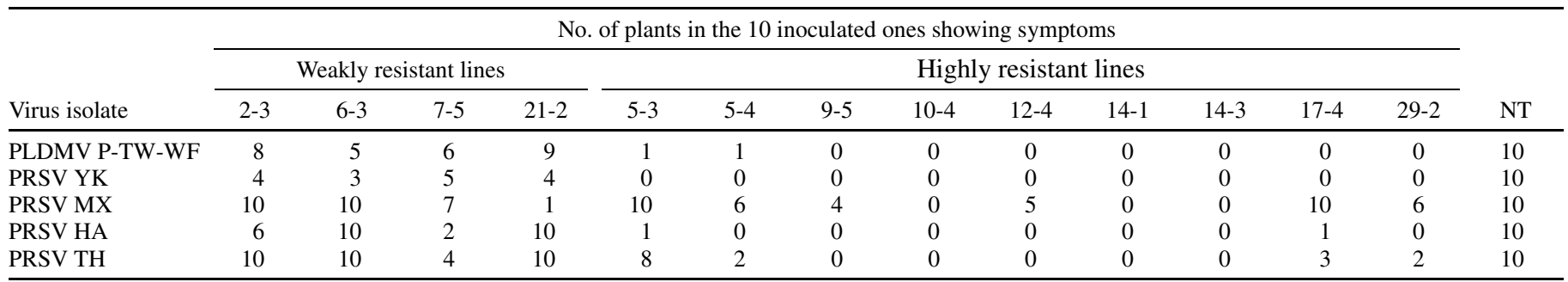

a Symptoms developed in transgenic lines were compared with those of nontransgenic papaya (NT) plants at 28 days postinoculation. Ten plants from each line were inoculated with individual PLDMV P-TW-WF or PRSV strains, including PRSV YK, a Taiwanese strain (44); PRSV HA (22), a Hawaiian strain; PRSV MX, a Mexican strain; and PRSV TH, a Thai strain (2). An NT plant was used as a control. 
A
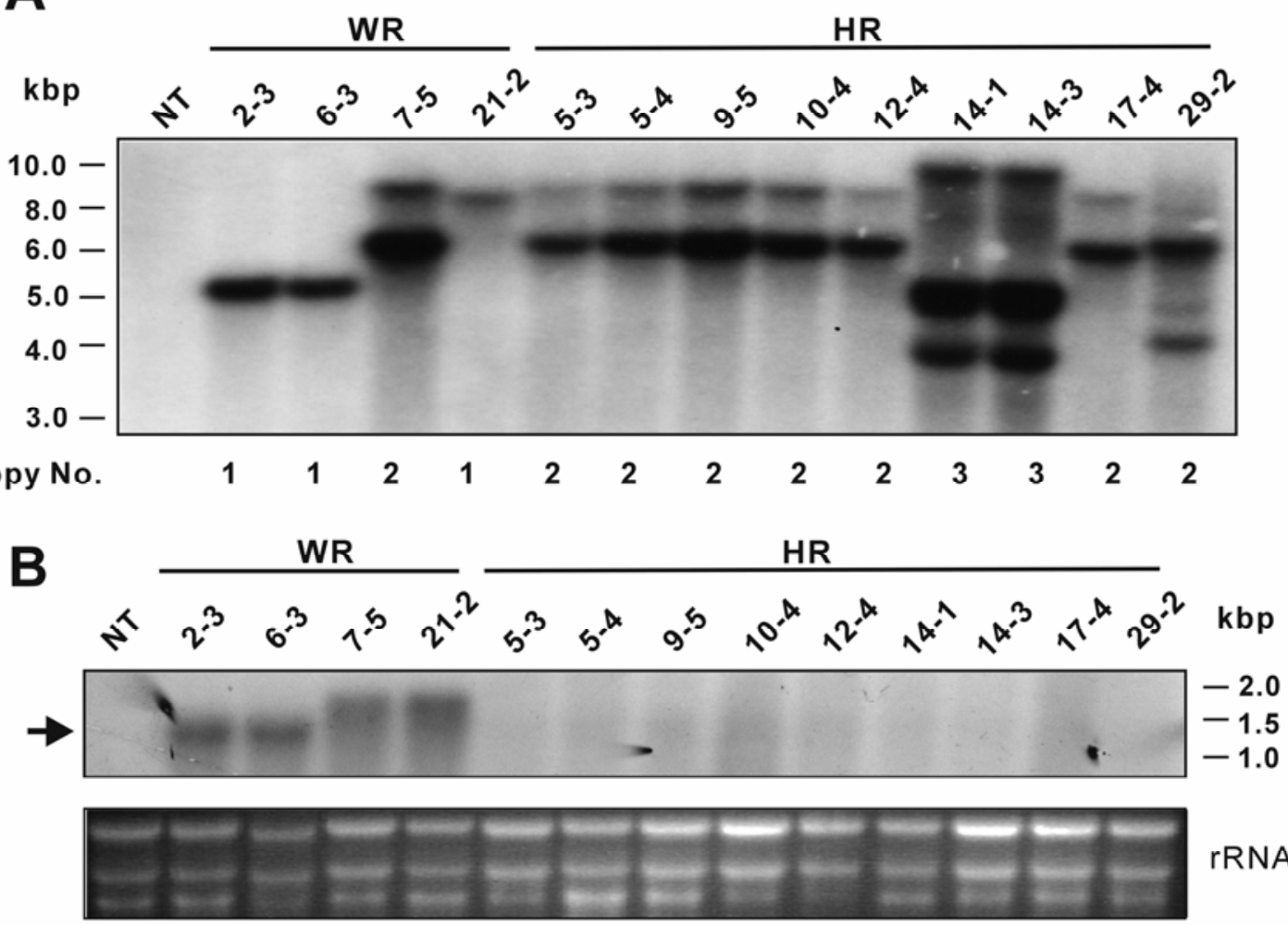

rRNA

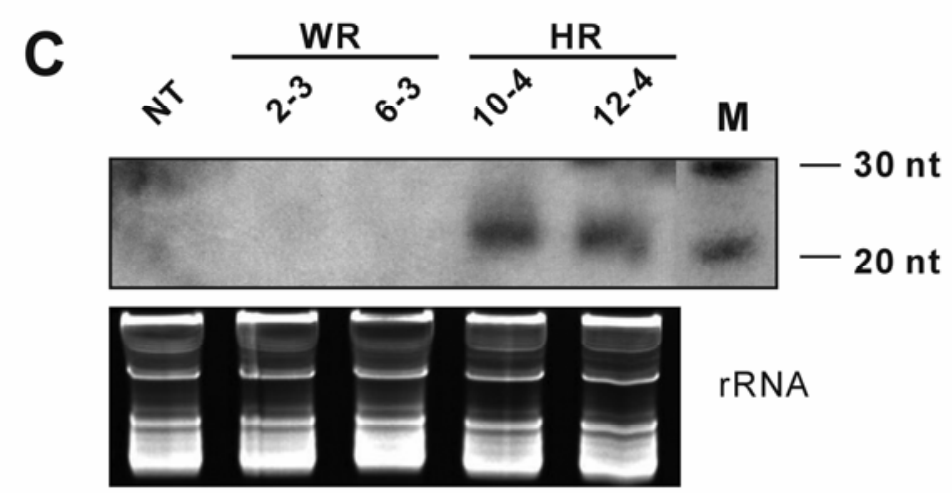

Fig. 3. Insertion of the transgenic construct in $\mathrm{R}_{0}$ transgenic papaya lines analyzed by Southern hybridization, and accumulation of transgenic transcript and small interfering RNA (siRNA) detected by northern hybridization. A, Analysis of the copy numbers of the chimeric construct in transgenic papaya lines as detected by Southern hybridization. The copy numbers (Copy No.) are indicated at the bottom of each lane. B, Expression levels of transgene transcript of weakly resistant (WR) and highly resistant (HR) lines detected by northern hybridization. Nontransgenic papaya (NT) was used as a negative control and the arrow indicates where the expected chimeric transcript should migrate. The quantities of the total RNA ( $15 \mu \mathrm{g} / \mathrm{lane})$ loaded were monitored by ethidium bromide staining. C, siRNA accumulations of chimeric construct in the two WR lines (2-3 and 6-3) and two HR lines (10-4 and 12-4) were analyzed by PY16-specific probe. RNA Decade Marker system (Ambion Inc., Austin, TX) was used as marker in this experiment.

TABLE 3. Segregation analysis of the transgenic resistance to Papaya leaf-distortion mosaic virus (PLDMV) of the back-crossed $\left(\mathrm{BC}_{1}\right)$ and hybrid $\left(\mathrm{F}_{1}\right)$ progenies of the two highly resistant transgenic papaya lines carrying the truncated coat protein fragments of PLDMV strain P-TW-WF and Papaya ringspot virus (PRSV) strain YK

\begin{tabular}{|c|c|c|c|c|c|c|c|}
\hline \multirow[b]{2}{*}{ Progenies of crossing ${ }^{\mathrm{a}}$} & \multirow[b]{2}{*}{ Copy no. } & \multicolumn{2}{|c|}{$\begin{array}{l}\text { No. of plants showing different phenotypes } \\
\text { at } 14 \text { days postinoculation }\end{array}$} & \multirow[b]{2}{*}{ Segregation ratio } & \multirow[b]{2}{*}{ Insert locus $^{\mathrm{b}}$} & \multirow[b]{2}{*}{$\chi^{2}$} & \multirow[b]{2}{*}{$P^{\mathrm{c}}$} \\
\hline & & Symptomless & Mosaic and vein-clearing & & & & \\
\hline $10-4 \times \mathrm{TH}\left(\mathrm{BC}_{1}\right)$ & 2 & 292 & 108 & $3: 1$ & 2 & 0.853 & 0.356 \\
\hline $12-4 \times \mathrm{TH}\left(\mathrm{BC}_{1}\right)$ & 2 & 201 & 198 & $1: 1$ & 1 & 0.022 & 0.881 \\
\hline $12-4 \times \operatorname{SR}\left(F_{1}\right)$ & 2 & 258 & 242 & $1: 1$ & 1 & 0.512 & 0.474 \\
\hline Tainung No. 2 & $\ldots$ & 0 & 56 & $\ldots$ & $\ldots$ & $\ldots$ & $\ldots$ \\
\hline
\end{tabular}

${ }^{a} \mathrm{BC}_{1}$ and $\mathrm{F}_{1}$ progenies were derived from crossing the transgenic lines with non-transgenic papaya (NT) cv. Thailand (TH) and Sunrise (SR) plants, respectively.

${ }^{\mathrm{b}}$ Predicted number of insert locus.

c Probability of goodness of fit was set at a significant level of 0.05 . 
PRSV YK CP transgene. It is possible that the ability to overcome transgenic resistance by PRSV 5-19 may be due to the involvement of the HC-Pro, which is a silencing suppressor $(1,24)$ and virulence enhancer (41). If a strain contains a stronger HCPro that can suppress PTGS completely, the breakdown of the transgenic resistance would not necessarily be related to the transgene homology. Whether the HC-Pro gene of PRSV 5-19 is actually responsible for overcoming the single resistance to PRSV and the double resistance to PRSV and PLDMV is being analyzed.

In summary, using an untranslatable chimeric $\mathrm{CP}$ construct to induce PTGS, we have successfully obtained transgenic papaya lines resistant to PLDMV P-TW-WF and PRSV YK. Furthermore, $\mathrm{BC}_{1}$ and $\mathrm{F}_{1}$ progenies resistant to PLDMV P-TW-WF and PRSV YK were obtained by crossing the transgenic lines with cV. Thailand and cv. Sunrise, respectively. The $\mathrm{F}_{1}$ progenies, which have horticultural properties most similar to the popular commercial cv. Tainung No. 2, are under field tests to evaluate their commercial merits. The transgenic lines we have described have the potential of being important in managing PLDMV and PRSV in Taiwan and other regions of the world.

\section{ACKNOWLEDGMENTS}

This research was supported by grants (92AS-4.2.1-FD-Z2, 93AS4.2.1-FD-Z1, 94AS-5.1.4-FD-Z1, and 95AS-6.1.3-FD-Z1) from the Council of Agriculture, Taiwan, R.O.C.

\section{LITERATURE CITED}

1. Anandalakshmi, R., Pruss, G. J., Ge, X., Marathe, R., Mallory, A. C., Smith, T. H., and Vance, V. B. 1998. A viral suppressor of gene silencing in plants. Proc. Natl. Acad. Sci. USA 95:13079-13084.

2. Bau, H. J., Cheng, Y. H., Yu, T. A., Yang, J. S., and Yeh, S. D. 2003. Broad-spectrum resistance to different geographic strains of Papaya ringspot virus in coat protein gene transgenic papaya. Phytopathology 93:112-120.

3. Bau, H. J., Cheng, Y. H., Yu, T. A., Hsiao, C. H., and Yeh, S. D. 2004. Field evaluation of transgenic papaya lines carrying the coat protein gene of Papaya ringspot virus in Taiwan. Plant Dis. 88:594-599.

4. Bau, H. J., Kung, Y. J., Raja, J. A. J., Chan, S. C., Chen, K. C., Chen, Y. K., Wu, H. W., and Yeh, S. D. 2008. Potential threat of a new pathotype of Papaya leaf distortion mosaic virus infecting transgenic papaya resistant to Papaya ringspot virus. Phytopathology 98:848-858.

5. Baulcombe, D. C. 1996. RNA as a target and an initiator of posttranscriptional gene silencing in transgenic plants. Plant Mol. Biol. 32:7988 .

6. Baulcombe, D. C. 2007. Molecular biology. Amplified silencing. Science 315:199-200

7. Bucher, E., Lohuis, D., van Poppel, P. M., Geerts-Dimitriadou, C., Goldbach, R., and Prins, M. 2006. Multiple virus resistance at a high frequency using a single transgene construct. J. Gen. Virol. 87:3697-3701.

8. Chan, S. J., Bau, H. J., and Yeh, S. D. 1999. Production of the antibody to bacterial expressed coat protein of Papaya leaf-distortion mosaic virus. Plant Pathol. Bull. 8:182.

9. Cheng, Y. H., Yang, J. S., and Yeh, S. D. 1996. Efficient transformation of papaya by coat protein gene of Papaya ringspot virus mediated by Agrobacterium following liquid-phase wounding of embryogenic tissues with carborundum. Plant Cell Rep. 16:127-132.

10. Chiang, C. H., Wang, J. J., Jan, F. J., Yeh, S. D., and Gonsalves, D. 2001. Comparative reactions of recombinant papaya ringspot viruses with chimeric coat protein (CP) genes and wild-type viruses on CP-transgenic papaya. J. Gen. Virol. 82:2827-2836.

11. Conover, R. A. 1976. A program for development of papaya tolerant to the distortion ringspot virus. Proc. Fla. State Hortic. Soc. 89:229-231.

12. Conover, R. A., and Litz, R. E. 1978. Progress in breeding papaya with tolerance to Papaya ringspot virus. Proc. Fla. State Hortic. Soc. 91:182184.

13. Davis, M. J., and Ying, Z. 2004. Development of papaya breeding lines with transgenic resistance to Papaya ringspot virus. Plant Dis. 88:352358.

14. English, J. J., and Baulcombe, D. C. 1997. The influence of small changes in transgene transcription on homology-dependent virus resistance and gene silencing. Plant J. 12:1311-1318.

15. Fauquet, C. M., Mayo, M. A., Maniloff, J., Desselberger, U., and Ball, L.
A. 2005. Virus taxonomy: classification and nomenclature of viruses. In: Eighth Rep. Int. Committee on Taxonomy of Viruses.

16. Fitch, M. M. M., Manshardt, R. M., Gonsalves, D., Slightom, J. L., and Sanford, J. C. 1990. Stable transformation of papaya via microprojectile bombardment. Plant Cell Rep. 9:189-194.

17. Fitch, M. M. M., Manshardt, R. M., Gonsalves, D., Slightom, J. L., and Sanford, J. C. 1992. Virus resistance papaya plants derived from tissues bombarded with the coat protein gene of Papaya ringspot virus. Bio/Technology 10:1466-1472.

18. Fuchs, M., and Gonsalves, D. 1995. Resistance of transgenic hybrid squash ZW-20 expressing the coat protein genes of Zucchini yellow mosaic virus and Watermelon mosaic virus 2 to mixed infections by both potyviruses. Bio/Technology 13:1466-1473.

19. Fuchs, M., Tericoli, D. M., Carney, K. J., Schesser, M., McFerson, J. R., and Gonsalves, D. 1998. Comparative virus resistance and fruit yield of transgenic squash with single and multiple coat protein genes. Plant Dis. 82:1350-1356.

20. Gonsalves, D. 1998. Control of papaya ringspot virus in papaya: a case study. Annu. Rev. Phytopathol. 36:415-437.

21. Gonsalves, D. 2002. Coat protein transgenic papaya: "acquired" immunity for controlling Papaya ringspot virus. Curr. Top Microbiol. Immunol. 266:73-83.

22. Gonsalves, D., and M. Ishii. 1980. Purification and serology of Papaya ringspot virus. Phytopathology 70:1028-1032.

23. Jan, F. J., Fagoaga, C., Pang, S. Z., and Gonsalves, D. 2000. A single chimeric transgene derived from two distinct viruses confers multi-virus resistance in transgenic plants through homology-dependent gene silencing. J. Gen. Virol. 81:2103-2109.

24. Kasschau, K. D., and Carrington, J. C. 1998. A counterdefensive strategy of plant viruses: Suppression of posttranscriptional gene silencing. Cell 95:461-470.

25. Kawano, S., and Yonaha, T. 1992. The occurrence of Papaya leafdistortion mosaic virus in Okinawa. Tech. Bull. FFTC 132:13-23. Food and Fertilizer Technology Center for the Asian and Pacific Regions, Taipei, Taiwan, R.O.C.

26. Kunz, C., Schob, H., Stam, M., Kooter, J. M., and Meins, F. J. 1996 Developmentally regulated silencing and reactivation of tobacco chitinase transgene expression. Plant J. 10:437-450.

27. Lines, R. E., Persley, D., Dale, J. L., Drew, R., and Bateson, M. F. 2002. Genetically engineered immunity to Papaya ringspot virus in Australian papaya cultivars. Mol. Breed. 10:119-129.

28. Lius, S., Manshardt, R. M., Fitch, M. M. M., Slightom, J. L., Sanford, J. C., and Gonsalves, D. 1997. Pathogen-derived resistance provides papaya with effective protection against Papaya ringspot virus. Mol. Breed. 3:161-168.

29. Maoka, T., and Hataya, T. 2005. The complete nucleotide sequence and biotype variability of Papaya leaf-distortion mosaic virus. Phytopathology 95:128-135.

30. Maoka, T., Kashiwazaki, S., Tsuda, S., Usugi, T., and Hibino, H. 1996. Nucleotide sequence of the capsid protein gene of Papaya leaf-distortion mosaic potyvirus. Arch. Virol. 141:197-204.

31. Mueller, E., Gilbert, J., Davenport, G., Brigneti, G., and Baulcombe, D. C. 1995. Homology-dependent resistance: Transgenic virus resistance in plants related to homology-dependent gene silencing. Plant J. 7:10011013.

32. Pang, S. Z., Jan, F. J., Carney, K., Stout, J., Tricoli, D. M., Quemada, H. D., and Gonsalves, D. 1996. Post-transcriptional transgene silencing and consequent tospovirus resistance in transgenic lettuce are affected by transgene dosage and plant development. Plant J. 9:899-909.

33. Purcifull, D. E., Edwardson, J. R., Hiebert, E., and Gonsalves, C. 1984. Papaya ringspot virus. CMI/AAB Descriptions of Plant Viruses, No. 84.

34. Rogers, S. G., Horsh, R. B., and Fraley, R. T. 1986. Gene transfer in plants: Production of transformed plants using Ti-plasmid vectors. Methods Enzymol. 118:627-640.

35. Shukla, D. 1994. The Potyviridae. CAB International, Wallingford, UK.

36. Sijen, T., Wellink, J., Hiriart, J. B., and Van Kammen, A. 1996. RNAmediated virus resistance: role of repeated transgenes and delineation of targeted regions. Plant Cell 8:2277-2294.

37. Souza, J. M. T., Tennant, P. F., and Gonsalves, D. 2005. Influence of coat protein transgene copy number on resistance in transgenic line 63-1 against papaya ringspot virus isolates. HortScience 40:2083-2087.

38. Tennant, P., Fermin, G., Fitch, M. M., Manshardt, R. M., Slightom, J. L., and Gonsalves, D. 2001. Papaya ringspot virus resistance of transgenic Rainbow and SunUp is affected by gene dosage, plant development, and coat protein homology. Eur. J. Plant Pathol. 107:645-653.

39. Tennant, P. F., Gonsalves, C., Ling, K. S., Fitch, M., Manshardt, R., Slightom, J. L., and Gonsalves, D. 1994. Differential protection against Papaya ringspot virus isolates in coat protein gene transgenic papaya and classically cross-protected papaya. Phytopathology 84:1359-1366.

40. Tricoli, D. M., Carney, K. J., Pussell, P. F., McMaster, J. R., Groff, D. W., 
Hadden, K. C., Himmel, P. T., Hubbard, J. P., Boeshore, M. L., and Quemada, H. D. 1995. Field evaluation of transgenic squash containing single or multiple virus coat protein gene constructs for resistance to Cucumber mosaic virus, Watermalon mosaic virus 2, and Zucchini yellow mosaic virus. Bio/Technology 13:1458-1465.

41. Tripathi, S., Bau, H. J., Chen, L. F., and Yeh, S. D. 2004. The ability of Papaya ringspot virus strains overcoming the transgenic resistance of papaya conferred by the coat protein gene is not correlated with higher degrees of sequence divergence from the transgene. Eur. J. Plant Pathol. 110:871-882.

42. Tripathi, S., Suzuki, J., and Gonsalves, D. 2007. Development of genetically engineered resistant papaya for papaya ringspot virus in a timely manner: A comprehensive and successful approach. Methods Mol. Biol. 354:197-240.

43. Vaucheret, H., Palauqui, J. C., Elmayan, T., and Moffatt, B. 1995. Molecular and genetic analysis of nitrite reductase co-suppression in transgenic tobacco plants. Mol. Gen. Genet. 248:311-317.

44. Wang, C. H., and Yeh, S. D. 1997. Divergence and conservation of the genomic RNAs of Taiwan and Hawaii strains of papaya ringspot potyvirus. Arch. Virol. 142:271-285.

45. Wang, H. L., Wang, C. C., Chiu, R. J., and Sung, M. H. 1978 Preliminary study on Papaya ringspot virus in Taiwan. Plant Prot. Bull. 20:133-140.

46. Wang, H. L., Yeh, S. D., Chiu, R. J., and Gonsalves, D. 1987. Effectiveness of cross-protection by mild mutants of Papaya ringspot virus for control of ringspot disease of papaya in Taiwan. Plant Dis. 71:491-497.

47. Yang, J. S., and Ye, C. A. 1992. Plant regeneration from petioles of in vitro regenerated papaya (Carica papaya L.) shoots. Bot. Bull. Acad. Sin. 33:357-381.

48. Yeh, S. D., and Gonsalves, D. 1984. Evaluation of induced mutants of Papaya ringspot virus for control by cross protection. Phytopathology 74:1086-1091.

49. Yeh, S. D., and Gonsalves, D. 1985. Translation of Papaya ringspot virus RNA in vitro: detection of a possible polyprotein that is processed for capsid protein, cylindrical-inclusion protein, and amorphous-inclusion protein. Virology 143:260-270.

50. Yeh, S. D., and Gonsalves, D. 1994. Practices and perspective of control of Papaya ringspot virus by cross-protection. Adv. Dis. Vector Res. 10:237-257.

51. Yeh, S. D., Gonsalves, D., and Provvidenti, R. 1984. Comparative studies on host range and serology of papaya ringspot virus and water melon mosaic virus 1. Phytopathology 74:1081-1085.

52. Yeh, S. D., Gonsalves, D., Wang, H. L., Namba, R., and Chiu, R. J. 1988. Control of Papaya ringspot virus by cross protection. Plant Dis. 72:375380 .

53. Yeh, S. D., Jan, F. J., Chiang, C. H., Doong, T. J., Chen, M. C., Chung, P. H., and Bau, H. J. 1992. Complete nucleotide sequence and genetic organization of Papaya ringspot virus RNA. J. Gen. Virol. 73:2531-2541.

54. Yonaha, T., Yonemori, S., and Tamori, M. 1976. Relation between the flight occurrence of alate aphids and the spread of papaya virus disease in the field. Okinawa Agric. 14:7-15.

55. Yu, T. A., Yeh, S. D., and Yang, J. S. 2001 Effects of carbenicillin and cefotaxime on callus growth and somatic embryogensis from adventitious roots of papaya. Bot. Bull. Acad. Sin. 42:281-286. 